\title{
Ensuring environmental safety of the Baltic Sea basin
}

\author{
E.E. Smirnova, L.D. Tokareva \\ Department of Technosphere Safety, St. Petersburg State University of Architecture and Civil \\ Engineering, St. Petersburg, Russia
}

\begin{abstract}
The Baltic Sea is not only important for transport, but for a long time it has been supplying people with seafood. In 1998, the Government of the Russian Federation adopted Decree N 1202 "On approval of the 1992 Convention on the Protection of the Marine Environment of the Baltic Sea Region", according to which Russia approved the Helsinki Convention and its obligations. However, the threat of eutrophication has become urgent for the Baltic Sea basin and Northwest region due to the increased concentration of phosphorus and nitrogen in wastewater. This article studies the methods of dephosphation of wastewater using industrial waste.
\end{abstract}

\section{Introduction}

The main topic of the article is to show the possibility of using industrial waste as reagents to optimize the water treatment system of rivers flowing into the Baltic Sea and water reservoirs of the Northwest-region (including part of the water system of the Vologda Region associated with the Baltic basin) in order to bring the quality of wastewater to the international requirements established for the Baltic Sea. These measures will help to improve the environmental situation in the sphere of waste processing and thereby ensure an acceptable degree of trophicity of the reservoirs.

As far as self-purification processes in rivers and seas cannot provide complete recovery from wastewater pollution, the problem of removing phosphorus-containing compounds from wastewater and purifying wastewater is of great importance [1-3]. Considerable knowledge has already been gained in the world practice concerning removing phosphoruscontaining substances[4-7].

Conditions are created when activated sludge alternately passes through the anaerobic and aerobic zones, which stimulates the development of phosphorus bacteria in it to implement the technology of dephosphorization in the system of biological treatment. Besides, it is essential to comply with the condition of the presence of a sufficient amount of easily oxidizable organic substances in the original wastewater entering the anaerobic zone for effective biological purification from phosphorus using dephosphorization technology. This condition is especially relevant for Russia, where joint sewage disposal is generally utilized. Physical and mechanical and physicochemical properties, biological and combined cleaning methods (biochemical and biothermal) are widely used in the UK, USA, Japan, Germany, and Sweden[8]. 
Chemical treatment of municipal wastewater is directly related to eutrophication, which is the main problem of the Baltic Sea, one of the most sensitive basins to biological colonization in the world[9]. As a result of intensive agriculture, the amount of nitrogenphosphorus nutrients released into the Baltic Sea has increased by 7 times over the past 50 years. This has a serious ecological impact on the ecosystem and living organisms of the Baltic Sea basin.Nutrients from agriculture include ammonia $\left(\mathrm{NH}_{3}\right)$, nitrogen (nitrates $\left(\mathrm{NO}_{3}\right)$ and organic nitrogen), and phosphorus in phosphates compounds $\left(\mathrm{PO}_{4}\right)^{3-}$, manure storage, and silage heaps[10]. Since the 1900s, the Baltic Sea has passed from an oligotrophic state with clean water to a eutrophic state[11].

The main reason for the urgent need for chemical wastewater treatment is the water quality of the rivers of the Northwest region flowing into the Baltic Sea. This quality has greatly decreased, and it is far from being perfect when compared with the norms of SanPiN (Hygienic Rules and Regulations: Requirements for Surface Water Protection) 2.1.5.980-00 (2000). Thus, in particular, high content of organic matter was found in the Neva River (a-hexachlorane- $0.002 \mu \mathrm{g} / \mathrm{l}$ ). Maximum concentrations were found for zinc and copper - 15 times the ACC (the allowable concentration of contaminants)value ([11]: 16,137). A similar outcome takes place in the Northwestern region and the northwestern part of the Vologda region of the Baltic Sea basin. Since the Volga-BalticCanal connects the Volga and its tributaries with the Baltic, with Ladoga and Onega Lakes, we can talk about a single natural-artificial topos, the environmental safety of which is questioned by man. Approximately $10 \%$ of the Baltic Sea water basin contains water from the northern sloping part of the East European Plain. The watershed of three sea basins (Baltic, White, and Caspian) passes just within the boundaries of the Vologda region. In the west of the region, there are more than $87 \%$ of lakes whose waters are connected, if not directly, with the Baltic Sea basin (the Vytegra, Andoma, and Megra Rivers), then through rivers flowing in a latitudinal direction (for example, the Sukhona River). From the authors'point of view, through climatic changes that provide excessive moisture, geological profiles along the line of tectonic faults (the presence of ancient deep glacial lacustrine depressions and troughs of glacial water runoff), landslides, regressive erosion processes, surface and ground waters, waterlogging, and other hydrological processes of the Vologda region water systems have a direct impact on the water reservoirs of the North-western basin (through KubenskoeVozhe-Lache Lake In the Onega River).This is confirmed by the structure of the relief.Water-glacial streams passed through its lowered sections, and within the boundaries of these lowlands, lakes were formed, connected by channels.

As a result of the anthropogenic factor, the average annual concentrations of the main pollutants in the cascade of northern reservoirs of the RiverVolga and the Vologda region exceed the maximum permissible concentration (MPC) requirements for petroleum products, iron, manganese, phenols, zinc, the five-day biochemical oxygen demand $\left(\mathrm{BOD}_{5}\right)$, and nitrogen ammonium salts. The water quality of the Uglich reservoir (Uglich city) is characterized as "polluted"; Rybinskreservoir- as "polluted" and "dirty", and because of the wastewater from industrial enterprises "Severstal", Cherepovets SDPP, "Cherepovets Azot" and "Ammophos" (Cherepovets, Vologda Region), as "very dirty" (average annual and maximum content of ammonia nitrogen in water is up to $16 \mathrm{MPC}$, nitrite nitrogen up to 71 MPC; see www.ecodelo.org).The pollution of the RybinskSea with hazardous chemical, household, and industrial waste exceeds all standards. Soon this will lead to irreversible pollution of the reservoir. Water pollution with oil products was noted downstream the cities of Rybinsk and Tutaev, as well as in the area of Chkalovsk, where the average annual concentration of oil products has recently been up to 5-7 MPC. Corrosion wear of the metal structures of the Rybinsk Dam exceeds the permissible limits. In the event of a breakthrough of the Volga waters, the flooding of the acid sludge storage ponds of the Mendeleyev Oil Refinery after(Yaroslavl) is possible. 
The "algal bloom" is characterized by a change in the color of water with a predominance of green, which is caused by a high concentration of photosynthetic microorganisms and multicellular algae. Water quality has been significantly deteriorating. It becomes difficult to use it not only for drinking but also for recreational purposes. "Algal bloom" water is a favorable environment for the development of pathogenic microorganisms. According to the Commission of the Helsinki Convention (HELCOM), an increase of primary plankton production by an average of $30 \%$, an increase of organic carbon deposited at the bottom by $70-190 \%$ was recorded in the Baltic Sea[12]. The decrease in oxygen concentration has led to the destruction of macrobenthos in an area of approximately $100,000 \mathrm{~km}^{2}$ in the Baltic Sea and the Gulf of Finland[13].

The consumption of natural resources and the destruction of the environment are going to result in an extremely unfavorable (basic) scenario of unstable economic developmentincreasingly unpredictably [14-17]. In recent years, the water in the Baltic Sea has deteriorated as well as in the Gulf of Finland. Residents of coastal areas complain about socalled "algal bloom" of water in summer, which significantly degrades water quality and make it simply dangerous to use for recreational and domestic purposes. In the language of ecologists, we can say that the state of the Baltic Sea has changed from oligotrophic to eutrophic, that is, in the bottom layer of water, the oxygen concentration has sharply decreased to $2 \mathrm{mg} / \mathrm{l}$. This resulted in the degradation of the ecosystem of the sea, an unbalanced growth of algae, and so-called "algal bloom" of water.

The main nutrients that disrupt the development of the productivity of water reservoirs are phosphorus and nitrogen. If an excess of compounds of these substances comes into the reservoir, the production of plant biomass begins to increase uncontrollably. This is especially common in shallow waters with low current. The increase in plant biomass results in an increase in the proportion of putrefactive processes in the reservoir - its trophic status changes, which is accompanied by a deep restructuring of the entire ecosystem of the reservoir.

To stop the development of eutrophication processes, it is necessary to reduce the ingress of nitrogen and phosphorus into water reservoirs with household and industrial wastewater. According to the authors, the best option for wastewater dephosphotation is the use of mineral reagents, which are waste products of enterprises. In this case, two problems are solved at once: the removal of nutrients from wastewater and the disposal of industrial waste. The need for implementation of cleaning with chemicals is due to stricter cleaning requirements: on October 3, 2013, a Ministerial Declaration was signed in Copenhagen (Denmark), according to which phosphorus ingress to the Gulf of Finland should be reduced by $3.909 \mathrm{t} /$ year, and nitrogen - by $14.452 \mathrm{t} /$ year [12].

However, recently, many water facilities, including those located in the Baltic Sea, have experienced an increase in nutrient load. In accordance with the LOC-10 index, the Neva Bay area is considered to be an area of environmental emergency. Even a slight decrease in the amounts of nutrient input from catchment areas in recent years has not corrected the environmental situation, since long-term excess of these led to the development of cyanobacteria that are potentially harmful to the environment. The matter is when the bluegreen algae mass runs out of nutrients for its existence and begins to die, decomposition processes take away oxygen from the reservoir, and oxygen deficiency creates conditions for suffocation phenomena. In addition, some types of blooming blue-green algae can be toxic to human beings[18].

There is only one way out: to launch dephosphorization processes with the use of mineral reagents, i.e., waste from enterprises, which will reduce the cost of the reagents and simultaneously solve environmental problems with disposal. The need to carry out these works is due to the tightening of cleaning requirements. The previous technology did not allow reducing the amount of nutrients in the sewage.This requirement can be fulfilled only 
by changing the technological chain of water passage in aeration tanks.Some of these measures have already been taken. Biological treatment facilities are operating in the standard mode in Vologda, Totma, Cherepovets, VelikyUstyug, Chagoda.However, in general, about $30 \%$ of the region's wastewater is still discharged into water reservoirs without treatment. Due to the outdated design and hydraulic overload, only half of the treatment facilities provide the design mode of wastewater treatment. Water discharges from equipment flushing after homogenizing tanks pollute surface water bodies with organic and inorganic substances, and chemical reagents added as coagulants and flocculants during water treatment. Residual active chlorine near the outlet leads to the destruction of a significant part of microorganisms which are necessary for the selfpurification of water reservoirs. The greatest anthropogenic load is borne by water reservoirs on the banks of which large industrial centers are located: Sokol (rivers Sukhona, Pelshma, Makhrenga), Vologda (rivers Vologda, Sodema, Shogrash), and Cherepovets (rivers Koshta, Yagorba, Serovka). As for Vologda, the regulatory wastewater treatment is often questioned. This is due to the unsatisfactory performance of the facility itself. Large ratio of irregularity of wastewater flow during the day, poor design of existing sand traps, imperfect design of equipment at the stage of removing coarse impurities, miscalculations with the scopes of structures at the stage of biological treatment, physically and morally obsolete equipment of stationary pumping of activated sludge lead to violations of the technological scheme of wastewater treatment flow. The concentration of phosphorus in purified water sometimes reaches $2.0 \mathrm{mg} / 1$, i.e., above the design level (1.58)[19]. Different Authors indicate different values of phosphate concentration in water that are safe and do not cause eutrophication of reservoirs. These values are often associated with the concentration of nitrogen in the water. As for the content of orthophosphates in it, most often it has a value of $0.01 \mathrm{mg} / 1$ [20].

In the authors opinion, dephosphorization with the use of mineral reagents, i.e., industrial waste, can add to the positive dynamics of the content of phosphorus compounds in the water reservoirs of the Baltic Sea basin and prevent multiple exceeding of the threshold concentration of orthophosphates, leading to the development of eutrophication.

\section{$2 \quad$ Materials and methods}

The authors used industrial waste as reagents for phosphorus removal: ferrous sulfate phosphogypsum $\mathrm{CaSO}_{4} \cdot \mathrm{P}_{2} \mathrm{O}_{5}$ and $\mathrm{FeSO}_{4} 7 \mathrm{H}_{2} \mathrm{O}$. Phosphogypsum is an industrial waste product from sulfuric acid from OAO Ammofos in Cherepovets, therefore their cost is low. When phosphogypsum is used, the calcium ion reacts with phosphate ions in the presence of hydroxyl ions to form hydroxyl apatite. This mineral has a different chemical composition; the approximate formula of this reaction is as follows:

$$
5 \mathrm{CaSO}_{4}+4 \mathrm{OH}^{-}+3 \mathrm{HPO}_{4}{ }^{2-} \rightarrow \mathrm{Ca}_{5}(\mathrm{OH})\left(\mathrm{PO}_{4}\right)_{3}+5 \mathrm{SO}_{4}{ }^{2-}+3 \mathrm{H}_{2} \mathrm{O} .
$$

Phosphogypsum is a waste product of the mineral fertilizers production. On average, 4.3 -5.8 tons of phosphogypsum is formed per ton of phosphoric acid using the sulfuric acid method of apatite concentrate exposure, depending on the process technology and the raw materials used. Due to the large amount obtained during the production of mineral fertilizers, huge white hills of phosphogypsum are quickly accumulated. Storage of phosphogypsum in most cases is carried out in open areas in the form of dumps. Since the dumps are not protected from precipitation, a significant part of the substances contained in them is washed out and gets into the soil and surface water, which negatively affects the state of the environment[21,22]. Besides, if phosphogypsum is not neutralized with lime milk, gaseous fluorine is released into the atmosphere. Enterprises are forced to pay 
significant amounts for the storage of phosphogypsum - about $250 \mathrm{RUB} / \mathrm{t}$. This is the reason for the low price of phosphogypsum; its large amount dictates the need to introduce new ways of processing phosphogypsum.

Ferrous sulfate heptahydrate $\left(\mathrm{FeSO}_{4} \cdot 7 \mathrm{H}_{2} \mathrm{O}\right)$ is a waste product of several industrial enterprises in the Vologda Region. It is formed as a by-product during the etching of iron sheets, wires, and other metal products diluted with sulfuric acid. The equations for the hydrolysis of iron sulfate and the subsequent transition of the iron ion from $\mathrm{Fe}^{2+}$ to $\mathrm{Fe}^{3+}$ have the following form:

$$
\mathrm{FeSO}_{4}+2 \mathrm{H}_{2} \mathrm{O} \square \mathrm{Fe}(\mathrm{OH})_{2}+\mathrm{H}_{2} \mathrm{SO}_{4}
$$

$$
4 \mathrm{Fe}(\mathrm{OH})_{2}+\mathrm{O}_{2}+2 \mathrm{H}_{2} \mathrm{O} \square 4 \mathrm{Fe}(\mathrm{OH})_{3}
$$

$\mathrm{FeSO}_{4} \cdot 7 \mathrm{H}_{2} \mathrm{O}$ looks like bluish-green crystals; it is actively used in agriculture as a fungicide, as well as in the preparation of mineral paints. When large amounts of heptahydrate of iron sulfate, also called iron sulfate, are accumulated at landfills, it can cause burns to the plant layer and also change the physical properties of soils. A large amount of ferrous sulfate, its low cost, and low transportation costs serve as objective factors for the need for its processing.

The authors examined water samples according to basic methods, being guided by the following parameters: orthophosphate, any salt of orthophosphoric acid, mineral phosphorus in mineral substances, in particular, metal phosphates $\left(P_{\text {orthoph }}\right)$, total phosphorus $\left(P_{t o t}\right)$, dichromate chemical oxygen demand $\left(C O D_{\text {bichromate }) \text {, total biological }}\right.$ oxygen demand $\left(B O D_{t o t}\right.$, equals $\left.1.43 B O D_{5}\right)$, the suspended substances $(S S)$, ammonia and ammonium ions. Laboratories in which the research was carried out have licenses and certificates. The authors compared the data obtained with the results of similar studies[2325]. Model solutions of orthophosphates were studied as material. Multiple methods of regression analysis were used to process the results. The experiments were carried out at water treatment plants in Vologda and St. Petersburg (Northern Aeration Station in the village of Olgino) in several series with error analysis.

The selection of reagent injection points was carried out according to SNiP 2.04.03-85 upgraded as SN (Set of Rules. Sewerage. Pipelines and wastewater treatment plants) 31.13330 (2012). The manual states that chemical reagents can be injected into various points of the wastewater treatment process flow: at stage I - into a sand trap or primary settling tank; at stage II - in front of aeration tanks, directly into an aeration tank, in front of a secondary sedimentation tank, into a circulating activated sludge stream; at stage III (proper post-treatment) - after the secondary sedimentation tank.

The dose of the reagent at stage I was selected based on the ratio $|\mathrm{P}|:\left[\mathrm{Me}^{2+}\right]-$ from $1: 1$ to $1: 12$ in terms of volume of $100 \mathrm{sm}^{3}$. The required amount of reagent was weighed on an electronic balance in accordance with the specified ratios. During the operation, an aqueous solution of the reagent with a certain concentration was injected into the orthophosphate solution; the solution was settled and its optical density was determined on a photoelectric colorimeter. Then, using the calibration curve, the residual concentration of orthophosphates was calculated, and, using the stoichiometric ratio, it was recalculated to phosphorus according to the ratio of molar masses $\mathrm{M}_{\mathrm{PO}_{4}^{3-}}: \mathrm{M}_{\mathrm{p}}=3,065: 1$. Water samples were analyzed according to standard methods. Further, according to the formula:

$$
\text { Efficiency }=\left(\mathrm{C}_{\text {init }}-\mathrm{C}_{\text {residual }}\right) \times 100 \% \div \mathrm{C}_{\text {init }}
$$


the efficiency of removal of phosphorus compounds by iron sulfate was calculated[26]. Besides, the quality of wastewater treatment for total phosphorus, in addition to the dose of the reagent and its type, depends on the content of suspended solids and $\mathrm{pH}$ in the treated wastewater.

At stages II and III, according to clause 9.2.5.7 (SNiP 2012), when using reagents, the following ratios should be provided: to achieve a phosphorus phosphate concentration of less than $1 \mathrm{mg} / 1$, you need to take $2.7 \mathrm{~kg}$ of iron per $1 \mathrm{~kg}$ of precipitated phosphorus. The dose of reagents when introduced at the biological treatment stage was determined by the formula

$$
\mathrm{C}_{\text {reagent }} \div \mathrm{KC}_{\mathrm{P} \text { tot }}
$$

where $C_{\text {reagent }}$ is the required dose of the reagent, $\mathrm{mg} / 1$ (by $\mathrm{Me}_{2} \mathrm{O}_{3}$ ); $K$ - coefficient of increase of the stoichiometric ratio, calculated taking into account the determination by standard methods of the content of total phosphorus by $\mathrm{PO}_{4}^{3-}$ and metal reagent by metal oxide $\mathrm{Me}_{2} \mathrm{O}_{3}$ (accepted by Tabl., according to which the value of $K$ is indicated when using $\mathrm{FeSO}_{4}$ - iron sulfate in order to calculate the dose of reagents when introduced at the stage of biological purification); $\mathrm{C}_{\mathrm{P} \text { tot }}$ - concentration of total phosphorus in incoming water, $\mathrm{mg} / \mathrm{l}$ (by in the absence of data on the concentration of total phosphorus in the incoming water, it can be roughly taken by the formula:

$$
\mathrm{C}_{\mathrm{P}_{\text {tot }}}=(2-3) \mathrm{C}_{\mathrm{PO} 4}
$$

where $\mathrm{C}_{\mathrm{PO} 4}$ is phosphate concentration in incoming water, mg/l.

Table 1.Stoichiometric ratio increase factor for reagent dose determination.

\begin{tabular}{|c|c|}
\hline $\begin{array}{c}\text { Efficiency of } \\
\text { removalP }\end{array}$ tot $\%$ \\
\cline { 2 - 2 } & FeSO $_{4}$ (ferrous sulfate) is applied \\
\hline 60 & 0.15 \\
\hline 65 & 0.25 \\
\hline 70 & 0.33 \\
\hline 75 & 0.5 \\
\hline 80 & 0.66 \\
\hline 85 & 1 \\
\hline
\end{tabular}

\section{$3 \quad$ Results and discussion}

According to the administration of the city of St. Petersburg for 2018, the water in the Neva Bay area is characterized as "moderately polluted", while the water quality of the city's water reservoirs varies from "slightly polluted" to "strongly polluted". Monitoring the 
water area of the Neva Bay shows that the general trend in the supply of phosphorus and nitrogen is negative, but in 2019 their concentration began to increase again (Fig. 1) [27].

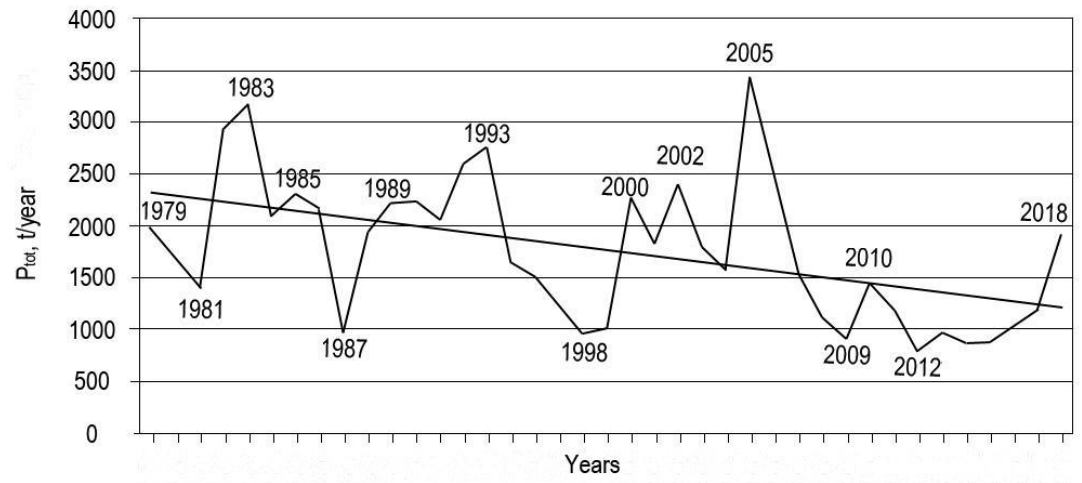

Fig. 1. Dynamics of total phosphorus ingress into the Neva Bay with the river flow of the Bolshaya Neva River and its binnacles.

Similar data were obtained throughout the Northwest region. Average annual concentrations of major pollutants in the cascade of northern reservoirs of this area exceed the requirements of the MPC standards in almost all indicators.

It is possible to consider the use of metallurgical waste for wastewater treatment using the example of treatment facilities in the Vologda Region. The histogram in Figure 2 allows to see data on the effectiveness of the removal of phosphorus compounds in sewage treatment plants in Vologda using traditional biological wastewater treatment technology.

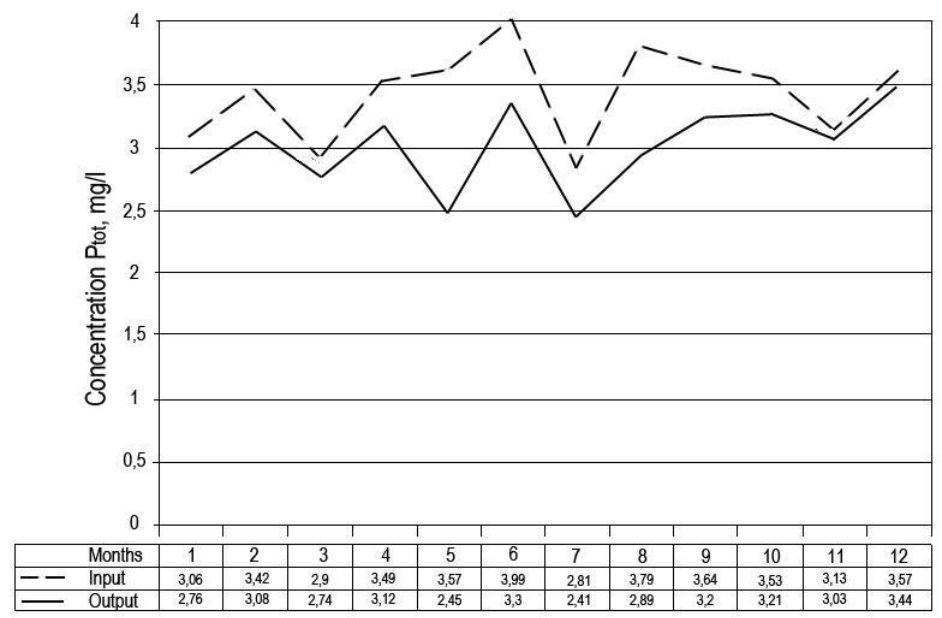

Fig. 2.The efficiency of phosphorus compounds removal in sewage treatment plants in Vologda (2012).

The abscissa represents the months of the year, the ordinate of the phosphate concentration measured at the points of entrance to the treatment facilities and the exit from them. The data show that in Vologda, the degree of wastewater treatment from phosphorus 
compounds using traditional biological technology prior to the reconstruction of treatment facilities was insufficient. It was several times lower than in Moscow and St. Petersburg [28].

The reconstruction and commissioning of additional facilities made it possible to establish the process of deep wastewater treatment from nutrients, as well as to introduce chemical treatment using reagents. It is optimal to use phosphogypsum and iron sulfate as such reagents. We can observe hills of phosphogypsum at almost any metallurgical enterprise or enterprise for the production of mineral fertilizers. Low cost is one of its main advantages and, besides this,phosphogypsum significantly improves the fertilizing properties of sludge, which can then be used in agriculture. When phosphogypsum is used as a reagent, the maximum dephosphorization effect is $56 \%$, which prevents the phosphorus content from decreasing to the required standard permissible discharge. At the same time, in the course of experiments on model aqueous solutions containing phosphorus of a given concentration, the efficiency of phosphate removal using phosphogypsum is very high. However, when the treatment of domestic wastewater is provided, its efficiency is significantly reduced since phosphogypsum reacts with other wastewater impurities. Consequently, the use of phosphogypsum as a reagent should be limited and applied to the treatment of industrial water with a high content of phosphorus compounds.

The most effective mineral reagent for wastewater dephosphorization is aluminum sulfate. It provides a consistently high effect up to $99.8 \%$ when treating model solutions with a reagent, $85 \%$ for household, and $98 \%$ for wastewater from livestock complexes. The maximum effect of dephosphotation when using an aluminum-containing reagent is observed when the ratio $\mathrm{Me}: \mathrm{P}=2: 1$. The efficiency of dephosphotation increases with the increase in temperature. However, this reagent, which is not a by-product of local production, requires additional costs for purchase, while the use of iron-containing reagents is economically justified.

The maximum effect of removing phosphorus compounds for all types of treated wastewater and model solutions is achieved as follows: for aluminum sulfate - at $\mathrm{pH}$ in the range of 5.5-6.5; for ferric chloride - at $\mathrm{pH}=3.5-5$ and 8-10. As the concentration of orthophosphates in the treated water increases, the optimal $\mathrm{pH}$ values shift to lower values. The maximum effect occurs at a temperature of $0-5^{\circ} \mathrm{C}$ and more than $30^{\circ} \mathrm{C}$ for ferric chloride; the consumption of the reagent to achieve the maximum effect of dephosphorization increases with an increase in the concentration of impurities in wastewater accompanying phosphorus[29,30].

Thus, it is preferable to use iron sulfate as a reagent for domestic wastewater. It is also a waste product from the production of metallurgical enterprises. Since such enterprises exist in many regions, the cost of iron sulfate as a reagent also remains low, and the cost of its delivery to treatment facilities is reduced. The costs of the enterprises themselves will also decrease, because they are forced to pay a state fee for each stored ton of waste, depending on their class of hazard.

When using chemical wastewater treatment methods, the reagent ions interact with soluble salts of phosphoric acid and with alkalis, forming large sediment particles that are removed from the system. These methods have several disadvantages: secondary metal contaminants which are formed after the use of the coagulant, increased acidity of water, an increase in the amount of sediment, and others; however, they provide the most stable effect under conditions of the variability of the phosphorus content in the source water.

The efficiency of phosphorus removal from wastewater depends not only on the composition of the water supplied to the treatment but also on the place in the technological scheme in which the reagent is introduced into the system. The graphs show that the greatest efficiency is achieved by introducing the reagent of iron sulfate and phosphogypsum into the system at the point located in front of the sand-silt collectors, 
where the highest concentration of phosphorus-containing substances is observed: here, is the most active formation of sediment, which can be easily removed from the system (Fig. 3 and 4) [31]

\section{$\mathrm{FeSO}_{4} \cdot 7 \mathrm{H}_{2} \mathrm{O}$}

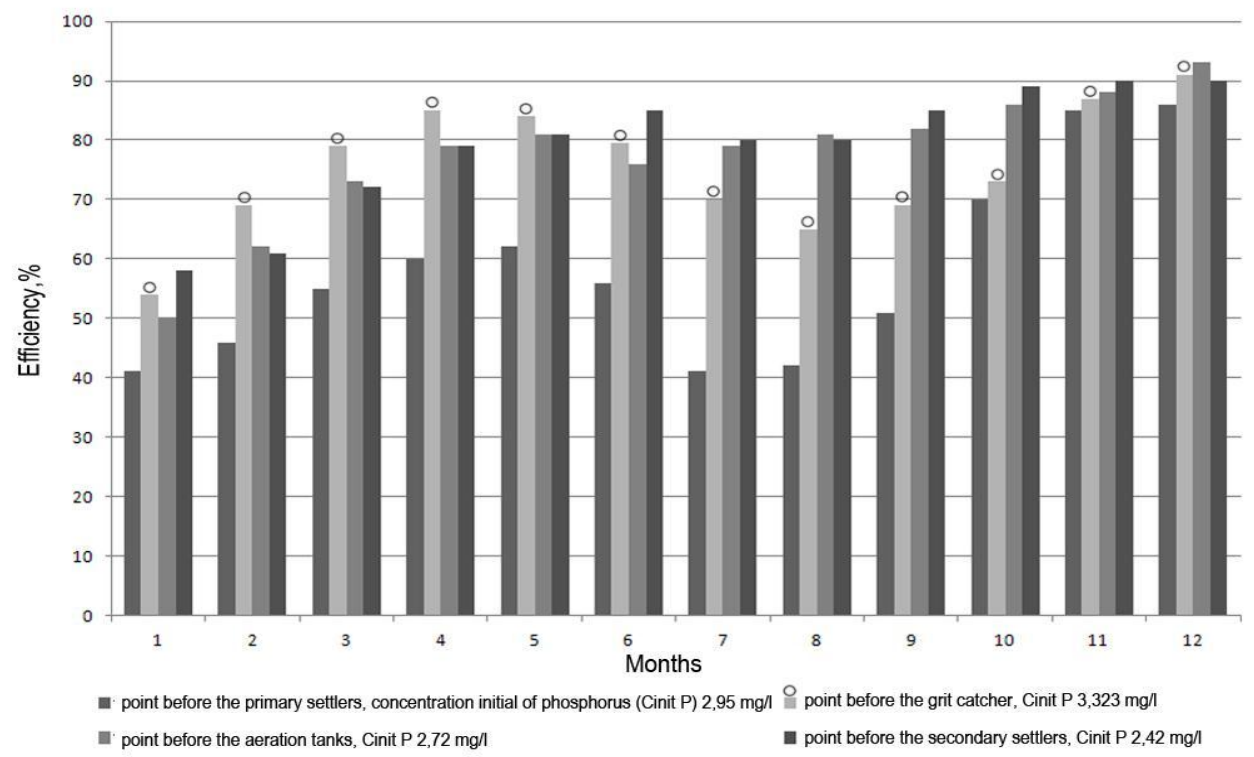

Fig.3.The efficiency of phosphorus compounds removal using iron sulfate as a reagent.

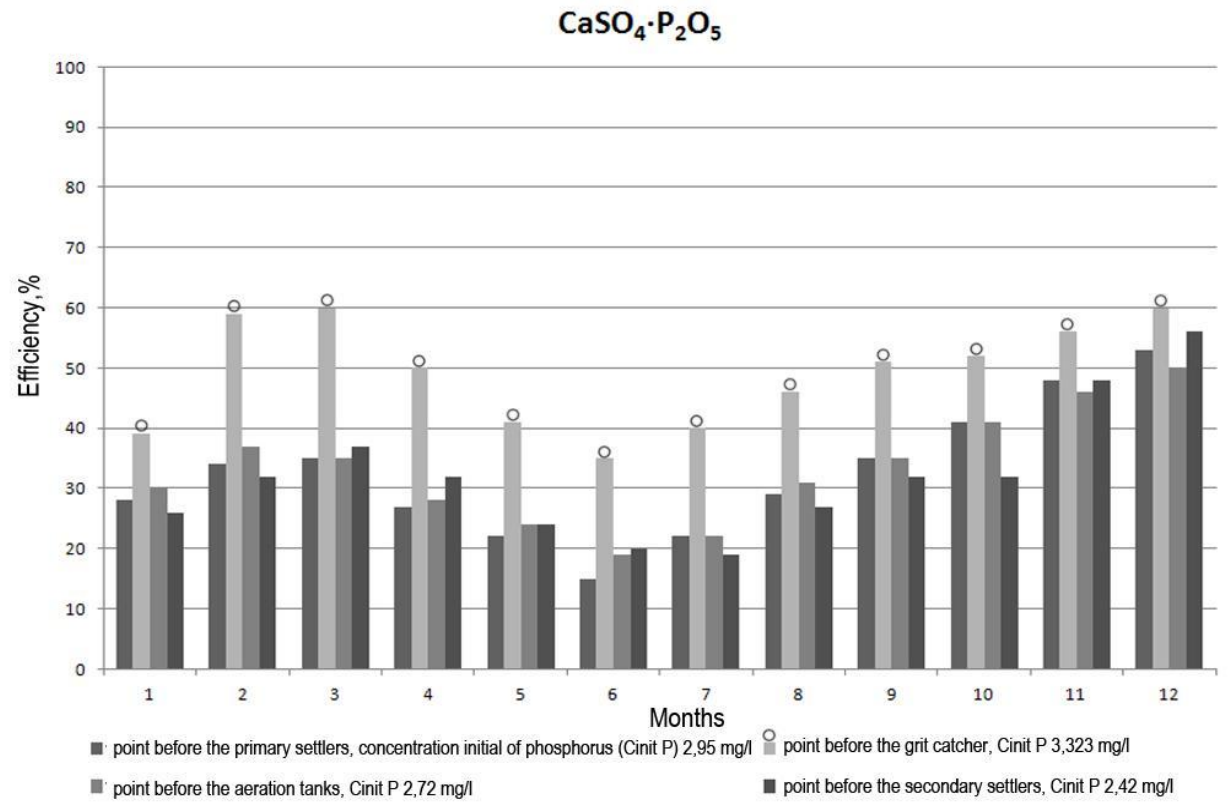

Fig. 4. The efficiency of phosphorus compounds removal using phosphogypsum as a reagent. 
When using a reagent (ferrous sulfate) in the sand trap, at a dose of $19.24 \mathrm{~g}$ of $\mathrm{Fe}^{2+} / \mathrm{m}^{3}$ (ratio $\mathrm{Fe}^{2+}: \mathrm{P}=3.6: 1$, initial phosphorus content is $3.323 \mathrm{mg} / \mathrm{l}$ )reagent provides a reduction in the concentration of phosphorus to MPC. Since the sand traps are aerated, the conversion of the iron ion from $\mathrm{Fe}^{2+}$ to $\mathrm{Fe}^{3+}$ takes place, and due to the turbulent mode of movement of wastewater entering the sand traps, good mixing with the coagulant solution occurs, i.e., no additional structures are required. According to the conducted calculations, the amount of oxygen required to convert $\mathrm{Fe}^{2+}$ to $\mathrm{Fe}^{3+}$ in an aerated sand trap is $4.37 \%$ of the total volume of oxygen supplied by aerators, which meets the requirements of the technological process using iron sulfate as a reagent.

As for the traditional biological method of phosphorus removal, in most cases, it is not possible to achieve precisely the steady removal of phosphates from wastewater up to the MPC regulatory requirements of fishery water reservoirs, since the correct process cannot be ensured. The main method of biological removal of phosphorus is the method with the anaerobic treatment of returnable recycling activated sludge. The use of this technology makes it possible to recover phosphates with an efficiency of about $90 \%$. In this system, phosphorus is removed with excess sludge and sludge water generated in the facility for anaerobic sludge treatment. When using alternate aerobic and anaerobic treatment of a mixture of waste liquid and activated sludge, the effect of removing phosphorus compounds reaches $70 \%$. In world practice, chemical treatment of wastewater is used in combination with biological treatment for the deep removal of phosphorus compounds. The authors consider this combination of processes to be optimal since it allows to achieve a higher quality of treated water than when using one of them.

\section{Conclusions}

Thus, it becomes clear that the currently existing treatment plants processing wastewater entering the Neva Bay area and Vologda Region although provide the necessary level of treatment, are, however, economically expensive. The inclusion of chemical reagents for dephosphotation in the process chain can significantly reduce costs and the anthropogenic load on the Baltic water area. This solution has already been successfully implemented in the Vologda Region and has shown its suitability for solving this problem and the greatest efficiency is achieved when a reagent is introduced into the system before sand-silt collectors. The main reagents suitable for dephosphotation are iron sulfate and phosphogypsum. These reagents are waste products from metallurgical production, which will also help to solve the problem of their disposal. Today, various schemes are used that combine a biological process and chemical precipitation in practice. The steadiest effect under conditions of change in the phosphorus content in the source water provides the combined use of both chemical and biological methods of dephosphorization. The use of such technology in the treatment facilities of the Baltic Sea basin will reduce the anthropogenic load and stop the eutrophication processes, which will favorably affect the state of the entire Baltic Sea.

\section{References}

1. P.M.J.Janssen, K.Meinema, , H.F.Roest van derBiological Phosphorus Removal: Manual for Design and Operation(Water and Waste Practitioner Series). (London: IWA Publ,2002).

2. E.Nassef Removal of phosphates from industrial wastewater by chemical precipitation,Engineering Science and Technology: An International Journal2(3), 409413 (2012). 
3. A.Szabó, I.Takács, S.Murthy, et al Significance of design and operational variables in chemical phosphorus removal, Water Environment Research80(5), 407-416 (2008).

4. APHA,Standard Methods for the Examination of Water and Wastewater. (Washington: American Public Health Association2005).

5. T.Asano, F. Burton, H. Leverenz, et al Water Reuse: Issues, Technologies, and Applications. (New York: McGraw-Hill Professional,2007).

6. G.Tchobanoglous, F.L.Burton, H.D.Stensel, et al Wastewater Engineering: Treatment and Reuse (McGraw-Hill Series in Civil and Environmental Engineering). (Boston: McGraw-Hill,2014).

7. C.F. Forster Wastewater Treatment and Technology. (London: Thomas Telford,2003).

8. M.Henze, P.Harremoes, J.Jansen, et al Wastewater Treatment: Biological and Chemical Processes,Springer, (2011).

9. HELCOM (Helsinki Commission)Eutrophication in the Baltic Sea. An integrated thematic assessment of the effects of nutrient enrichment and eutrophication in the Baltic Sea region,Baltic Sea Environment Proceedings, 115B, (2009).

10. J.P.Ducrotoy, M.ElliottThe science and management of the North Sea and the Baltic Sea: Natural history, present threats and future challenges,Marine Pollution Bulletin, 57, 8-21 (2008).

11. RMNR (Russian Ministry of Natural Resources)Public Report "State and Environmental Protection in Russian Federation”. (Moscow: Minprirody,2014).

12. HELCOM Chemical Munitions Dumped in the Baltic Sea, Baltic Sea Environment Proceedings, 142, (2013).

13. E.Smirnova, M.Alexeev The problem of dephosphorization using waste recycling,Environmental Science and Pollution Research,24(14), 12835-12846 (2017).

14. M.Slesarev, V.Telichenko, D. NguyenFormation of innovative methods for ecological safety systems of construction,MATEC Web of Conferences,251, 02010 (2018).

15. E. Smirnova Control capability of environmental safety in the context of 'green' construction paradigm,Espacios,39(22), 40 (2018).

16. E.Smirnova, V.Zaikin The problem of urban planning for sustainable development,E3S Web of Conferences,91, 05030 (2019).

17. M.Y. Slesarev, V.I.Telichenko The computer modeling concept in the paradigm of Green Standardization of ecological construction,IOP Conference Series: Materials Science and Engineering,456, 012126 (2018).

18. M.Karjalainen, J.Pääkkönen, H. Peltonen et al Nodularin concentrations in Baltic Sea zooplankton and fish during a cyanobacterial bloom, Marine Biology155(5), 483-491 (2008).

19. A.M.Zavgorodnij, O.A.Nikerova, E.V.Turkina, et al Sostojani ePrirodnoj Sredy Vologodskoj Oblasti v 2013 Godu [Report "The State of the Environment in the Vologda District in 2013"]. (Vologda: Department of Natural Resources and Environmental Protection2014).

20. F.R. Spellman, Handbook of Water and Wastewater Treatment Plant Operations. (Boca Raton: Taylor and Francis,2014).

21. E.Smirnova, Y. Larionova The problem of environmental safety during construction (analysis of construction impact on the environment),E3S Web of Conferences, 164, 07006 (2020). 
22. E.Smirnova, Y. Larionova, A. Larionov Sewer system optimization in housing and communal services,E3S Web of Conferences,157, 02002 (2020).

23. H.Altundoğan,F. Tümen Removal of phosphates from aqueous solutions by using bauxite II: The activation study,Journal of Chemical Technology and Biotechnology,78(7), 824-833 (2003).

24. S.Mohanty, J. Pradhan, S.Das, et al Removal of phosphorus from aqueous solution using aluminized red mud,International Journal of Environmental Studies,61(6), 687697 (2004).

25. G.Yilmaz, R.Lemaire, J. Keller, et al Simultaneous nitrification, gentrification, and phosphorus removal from nutrient-rich industrial wastewater using granular sludge,Biotechnology and Bioengineering,100(3), 529-541 (2008).

26. M.Alexeev,E.Fokicheva Removal of nutrients from wastewater of animal farms for prevention of increased eutrophic quality of water basins, Vestnik Grazhdanskih Inzhenerov - Bulletin of Civil Engineers1(36), 117-123 (2013).

27. I.A. Serebritsky (ed.)Report on the Environmental Situation in St Petersburg in 2018. (St. Petersburg: Sesame Print LLC,2018).

28. E .Smirnova, A.Larionov Justification of environmental safety criteria in the context of sustainable development of the construction sector, E3S Web of Conferences, 157, 06011 (2020).

29. E.A. Solov'jova Nitrogen and Phosphorus Removal from Municipal Waste Water. (Saarbrucken, DU: Lap Lambert Academic Publishing,2011).

30. M.Alexeev,E.Fokicheva Analysis of dephosphotation processes with application of mineral reagents, Vestnik Grazhdanskih Inzhenerov - Bulletin of Civil Engineers,3(44), 168-174 (2014).

31. M. Alekseev, E. Smirnova Wastewater of north-west Russia as a threat to the Baltic, Journal of Environmental Engineering and Science,11(3), 67-78 (2016). 